\title{
ТЕХНОЛОГИЧЕСКОЕ РАЗВИТИЕ ПРЯМЫХ ИНОСТРАННЫХ ИНВЕСТИЦИЙ И ЭКОНОМИКИ
}

\section{TECHNOLOGICAL DEVELOPMENT OF FOREIGN DIRECT INVESTMENT AND ECONOMY}

\section{Hajiyev Fuad Ogtay oglu}

Summary. The article examines the features of improving the use of foreign direct investment in the technological development of the high economy. The author considers the impact of direct foreign investment on the application of new and leading technologies in the country, the calculation of the relationship between research and development costs and foreign investment, the factors of effective attraction of advanced technologies through foreign investors, etc. The results of the article are presented at the end of the article.

Keywords: foreign capital, technology use mechanism, assessment direction, improvement.

\author{
Гаджиев Фуад Огтай оглы \\ Докторант, Азербайджанский университет \\ кооперации (2. Баку) \\ economy.f@mail.ru
}

Аннотация. В статье исследуются особенности совершенствования использования прямых иностранных инвестиций в технологическом развитии высокой экономики. Автор рассматривает влияние прямых иностранных инвестиций на применение новых и передовых технологий в стране, расчет взаимосвязи между затратами на исследования и разработки и иностранными инвестициями, факторы эффективного привлечения передовых технологий через иностранных инвесторов и др. Результаты статьи представлены в конце статьи.

Ключевые слова: иностранный капитал, механизм использования технологий, направление оценивания, совершенствование.
H аряду с важными факторами, влияющими на развитие мировой экономики в условиях глобализации, эффективное использование прямых инвестиций также играет важную роль. Прямые иностранные инвестиции имеют большое влияние на научное и техническое развитие стран и способствуют успешному развитию национальных экономик. В статье исследуются вопросы, связанные с эффективным использованием иностранных инвестиций, освоением новых технологий, выдвигаются практические предложения.

\section{Оченивание иностранного капита^а как фактора повышения конкУрентоспособности проАУкции}

При реализации проектов за рубежом страны, которые получают инвестиции, как правило, используют наиболее выгодное соотношение существующих факторов производства (технологий, используемых в виде лицензий и ноу-хау), включая все технологии, что позволяет осуществлять более продвинутые иностранные инвестиции.

При этом местные сотрудники предприятия, при организации производства за счет иностранных инвестиций, имеют возможность познакомиться с зарубежным оборудованием и технологиями, освоить более передовые методы организации и управления работой. Это может помочь в распространении информации о технологиях по неформальным каналам, хотя и частично, для распространения новых знаний даже среди профессионалов, не являющихся сотрудниками, в стране, получающей прямые иностранные инвестиции (ПИИ). Также следует отметить, что информация об иностранных технологиях может передаваться от предприятий, получающих иностранные инвестиции, местным поставщикам (см. Таблица 1). Одним из важнейших способов в направлении применения технологий, привезенных в страну иностранными инвесторами, является расширение масштаба «эффекта распространения знаний», связанного с иностранными инвестициями.

Следует отметить, что применение зарубежных технологий и экспорт капитала положительно сказываются на приобретении новых знаний. Это позволяет местным производителям повышать уровень технологий, используемых местными предприятиями в текущей ситуации под влиянием информации о более передовых технологиях. В то же время отсутствие в стране соответствующих специалистов, способных применять технологии, используемые иностранными инвесторами, может негативно сказаться на экономическом развитии тех стран, которые получают иностранные инвестиции. При изучении влияния иностранных инвестиций на международный обмен технологиями следует отметить, что существует связь между объемом затрат 
Таблица 1. Влияние привлечения прямых иностранных инвестиций на применение иностранных технологий по странам

\begin{tabular}{|c|c|}
\hline Прямой эффект & Косвенный эффект \\
\hline $\begin{array}{l}\text { Импорт более передовых производственных технологий (в виде } \\
\text { патентов, лицензий, ноу-хау). }\end{array}$ & $\begin{array}{l}\text { Влияние обучения специалистов (професиональное развитие } \\
\text { местных специалистов, личное общение квалифицированных } \\
\text { сотрудников с коллегами, работающими на других } \\
\text { предприятиях, при участии иностранных инвестиций, } \\
\text { перевод квалифицированных сотрудников предприятий } \\
\text { с иностранными инвестициями для работы на других } \\
\text { предприятиях) }\end{array}$ \\
\hline Импорт усовершенственного оборудования & $\begin{array}{l}\text { Отношения между предприятиями с иностранными } \\
\text { инвестициями с местными потребителями и местными } \\
\text { поставщиками продукции }\end{array}$ \\
\hline $\begin{array}{l}\text { Импорт более передовых технологий управления, включая } \\
\text { управление продажами }\end{array}$ & $\begin{array}{l}\text { Демонстрационный эффект } \\
\text { (Демонстрация технологий, используемых предприятиями } \\
\text { с иностранными инвестициями, и их последующее } \\
\text { подражание местным производителям) }\end{array}$ \\
\hline
\end{tabular}

Источник: таблица составлена автором

Таблица 2. Коэффициенты корреляции между стоимостью научно-конструкторских и экспериментальных работ и иностранными инвестициями (на 2019 год)

\begin{tabular}{|l|l|}
\hline Годовой приток прямых иностранных инвестиций в страну & Затраты на работу Нэп \\
\hline Объем годовых инвестиций из страны & 0,84549 \\
\hline Фонд иностранных инвестиций в стране & 0,91975 \\
\hline Резервы иностранных инвестиций в нашу недвижимость за рубежом & 0,82716 \\
\hline
\end{tabular}

Источник: таблица составлена автором

на научно-технические и экспериментальные работы (рассчитанных с учетом паритета покупательной способности) и объемом затрат прямых иностранных инвестиций за границу. Эти отношения (показывающие коэффициент корреляции более 0,8 ) очень близки изза желания стран с передовыми технологиями инвестировать, с одной стороны, и желания стран привлекать иностранные инвестиции, с другой.

Чрезвычайно важным для нас является, с одной стороны, размер доходов от использования интеллектуальной собственности из-за рубежа, а с другой наличие корреляции между прямыми иностранными инвестициями и резервами иностранных инвестиций. На наш взгляд, это можно объяснить стремлением стран с передовыми технологиями инвестировать и возможной связью между передачей технологий за границу и применением иностранных инвестиций.

Как видно из таблицы, наибольшая связь с научно-технической и экспериментальной работой в Азер- байджане наблюдается в объеме ежегодных инвестиций, покидающих страну.

Как известно из мировой практики, иностранные инвестиции являются основным каналом трансфера передовых технологий. Проникновение технологий признано во всем мире как процесс, в котором знания и технический опыт распространяются и принимаются во всех сферах экономики. Чтобы воспользоваться экономическими выгодами от экспорта капитала, ориентированного на инновации, необходимо принять специальные меры на организационном уровне. Этот процесс нельзя сводить к поставке новых машин или использованию новых промежуточных продуктов для уже существующей конкретной фирмы. Обеспечивает реорганизацию работы, восстановление цехов, совершенствование управления, разработку и маркетинг новых продуктов, и увеличение инвестиций в нематериальные активы.

Существует два типа проникновения технологий: прямое и косвенное. Проникновение прямых техноло- 
гий - это комплексная интеграция новых технологий в производственные процессы машин, оборудования и компонентов. Во-вторых, передача знаний, технического опыта и технологий таким образом, чтобы не обязательно покупать машины и оборудование с новыми технологиями. То есть иностранным инвестором в качестве инвестиции местному партнеру передаются только знания и методы производства.

На наш взгляд, важную роль в стимулировании деятельности иностранных инвесторов играют следующие:

- популяризация действительно успешных примеров инвестиционных проектов;

- повышение привлекательности высокотехнологичных секторов экономики;

- проведение международных мероприятий по привлечению прямых иностранных инвестиций, в том числе экономических и инвестиционных форумов, конференций, семинаров.

Инвестиция - это не только капитал, но и модернизация, основанная на современных технологиях, лучших формах управления и новом качестве жизни. Привлечение иностранных инвестиций способствует экономическому росту, модернизации национальной экономической системы и переходу к более высокому технологическому укладу.

Азербайджану, для становления одной из ведущих стран мира, необходим переход на новый путь инновационного развития. Такой переход может быть достигнут за счет обеспечения следующих показателей: развитая инфраструктура, высокий уровень благосостояния населения и значительная доля высокотехнологичного сектора страны в ВВП. Устранение научного разрыва между Азербайджаном и развитыми странами является актуальной задачей. В то же время Азербайджану необходимы масштабные инвестиции в современное производство, образование, знания и инновации.

\section{Эффективные формы привлечения прямых иностранных инвестиций}

Одной из эффективных форм привлечения прямых иностранных инвестиций для технологического развития национальных секторов экономики является создание иностранных и совместных предприятий. Следующие факторы имеют большое значение для создания иностранных и совместных предприятий [1, с. 3-4]:

1. Отсутствие экономических объемов, которые составляют основу финансовых источников в валовом национальном продукте, так как тенденция к сбережению настолько мала, что не позволяет формировать соответствующие финансовые фонды для обеспечения развития национальной экономики.

2. Отсутствие реальных сбережений, такое явление, связано с ресурсами, используемыми в производстве потребительских товаров, которые имеют меньшую тенденцию к использованию иностранных инвестиций.

3. Отсутствие валюты для привлечения иностранных источников.

Мировой опыт показывает, что развитие сети зарубежных и совместных предприятий способствует экономическому росту и вывозу капитала, положительно влияет на структуру валового внутреннего продукта, обеспечивая при этом эффективное использование местного сырья, насыщая внутренний рынок качеством товаров и услуг, и увеличивает экспертный потенциал страны. Деятельность иностранных и совместных предприятий способствует совместному использованию финансовых и материальных ресурсов, основанному на совместных усилиях всех экономических проблем.

В современных условиях иностранных инвесторов интересуют многие факторы, которые напрямую влияют на их решения по экспорту капитала: наличие или отсутствие экономической стабильности в стране, привлекательный рынок, подходящее сырье, инфраструктура, транспорт и т.д. Все это называется инвестиционным климатом. Наряду с этим, они анализируют инвестиционный климат. Однако инвестиционный климат действует не только как экономическая среда, но и как законная среда. Инвестор ищет среду, в которой он чувствует себя юридически под гарантией. Он хочет знать, какие законные отношения он увидит в новой стране, в которой будет инвестировать. В любой экономической ситуации, каким бы благоприятным ни был инвестиционный климат, приход иностранного инвестора в страну становится проблемой. Обратите внимание, что в мировой практике могут быть правительства, которые по разным причинам, открыто или косвенно демонстрируют свою политическую волю, исходя из принципа «приходит ли готовый инвестор, пусть приходит, если не приходит, то пусть не приходит» [5].

\section{К^ючевые приншипы Аля привлечения иностранного капита^а}

Несколько лет назад три швейцарских экономиста в результате встреч с ведущими организациями по международным средне- и долгосрочным (намеревалось более 5 лет) инвестициям, определили следующие 2 ключевых принципа для привлечения иностранного капитала [6]:

- В странах, ожидающих иностранных инвестиций, экономические законы и решения не должны меняться за одну ночь; 
- Хотя законы и решения не меняются, правительства не должны быть связаны этими законами и решениями.

Если принять во внимание эти два принципа, становится понятна причина проблем с привлечением иностранных инвестиций в другие сектора за пределами энергетического сектора Азербайджана. Кроме того, можно отметить, что нарушение этих двух принципов напрямую влияет на инвестиционные решения и самих владельцев капитала. Экономическая и политическая стабильность - важные условия для привлечения стабильного иностранного капитала в страну. Однако одного этого фактора недостаточно для привлечения иностранного капитала в страну.

В соответствии с международной практикой развивающиеся страны часто прибегают к политике индустриализации, производя продукцию для повседневного использования. Это связано с высоким спросом в этой сфере на внутреннем рынке. При этом отметим, что производство в ненефтяном секторе осуществляется небольшими предприятиями, не требующими больших капиталовложений и высоких технологий.

Активизация иностранной инвестиционной деятельности включает совершенствование и развитие форм привлечения иностранного капитала. Потоки иностранных инвестиций могут быть достигнуты за счет офшорных соглашений. Компенсационные соглашения являются одной из форм внешнеторговой сделки, предполагающие погашение кредитов и услуг на определенных условиях и в срок, когда целевые банковские кредиты предоставляются на развитие предприятий при условии их погашения поставщиками продукции. Такие сделки связаны с внешнеторговыми или промышленными предприятиями. Например, иностранный партнер может дать кредит стране и поставить оборудование для строительства промышленных и других объектов, а после ввода этого объекта в эксплуатацию может закупить в этой стране часть продукции, производимой в этой стране, в сумме, которая полностью покрывает сумму кредита, в том числе. В этом и суть договора о производственной компенсации. Наряду с этим, следует учитывать, что масштабные заключенные сделки требуют длительного времени не только для их реализации (исполнения), но и для погашения кредита (поставки готовой продукции), что приводит к износу оборудования и прочим негативным последствиям, и новым затратам. К таким соглашениям следует подходить с высоким профессионализмом и только после тщательного технико-экономического обоснования, учитывающего все отрицательные и положительные результаты.

\section{Зак^ючение}

На наш взгляд, для эффективного привлечения передовых технологий в нашу национальную экономику через иностранных инвесторов необходимо учитывать следующее:

1. Создание благоприятного климата для инвестициии. Любое нововведение требует времени, больших затрат, в стране с нестабильными правилами сложно инвестировать, так же результаты непредсказуемы.

2. Соотночение риска и дохода-ключевая характеристика любой инвестиции. Потенциальные выгоды от новой разработки могут быть очень высокими, но первый этап всегда требует больших вложений, а степень риск высокий. Доход вложения в инновацию является долгосрочным и обычно откладывается со временем. Это причина, по которой инвестор отговаривается от проекта, несмотря на высокую вероятность получения большой прибыли.

3. Отсутствие стабильной льготной инвестициионной политики. Во-первых, большинство инвесторов в первую очередь привлекают проекты и сферы, которые могут принести максимальную прибыль в краткосрочной перспективе, и область инноваций к ним не относится. Во-вторых, в Азербайджане нет специализированных учреждений в виде венчурных фондов, поддерживающих разработку и применение инновационных продуктов на ранних этапах внедрения. В-третьих, если вспомнить опыт ряда развивающихся стран, инновационные проекты в основном реализовывались по льготным налогам в свободных экономических зонах и на территориях, подготовленных к производству.

4. Достаточно высокие налоги, слабая защита интеллектуальной собственности, наличие бюрократических барьеров не позволяют иностранным предпринимателям инвестировать в подобные проекты.

\section{Выво $\triangle$}

В современных условиях существует большая потребность в расширении процесса привлечения прямых иностранных инвестиций, капитала и системы информационной поддержки иностранных инвесторов, которые являются важной частью структуры внешнеэкономических связей.

Эффективная медийная и коммуникационная стратегия государства должна обеспечить устранение неблагоприятных негативных тенденций для прибыльных иностранных инвестиций в страну, способствовать созданию имиджа Азербайджана. 


\section{ЛИТЕРАТУРА}

1. Воронин В.П. Инновационная деятельность предприятия Текст. / В.П. Воронин, Е.Н. Кравцова // Креативная экономика. — 2008. — № 6 (18).1. С. 3-8.;

2. Валдайцев С.В. Оценка бизнеса и инновации. М.: Иноформационно-издательский дом «Филинъ», 2007. - 336 с.

3. Мызрова 0.А. Развитие и современное состояние теории инноваций // Инновации. 2006. № . 7. с. 79-83.

4. Цветков В.Я., Омельченко А.С. Инновация и инновационный процесс как сложная система // Качество, инновации, образование. 2006. № 2. С. 11-14.

5. "Principles for Responsible Investment" consulting company's web page [Электронный ресурc]: URL: https://www.unpri.org/download?ac =1605. (Дата обращения: 07.06.2021).

6. The National Bureau of Economic Research. [Электронный ресурс]: URL: https://www.nber.org/digest/aug18/spillover-effects-international-joint-ventureschina (Дата обращения: 12.03.2021).

7. World Bank official web portal. [Электронный ресурс]: URL: http://data.worldbank.org/indicator/BM.GSR.ROYL.CD/countries (Дата 0бращения: 02.07.2021).

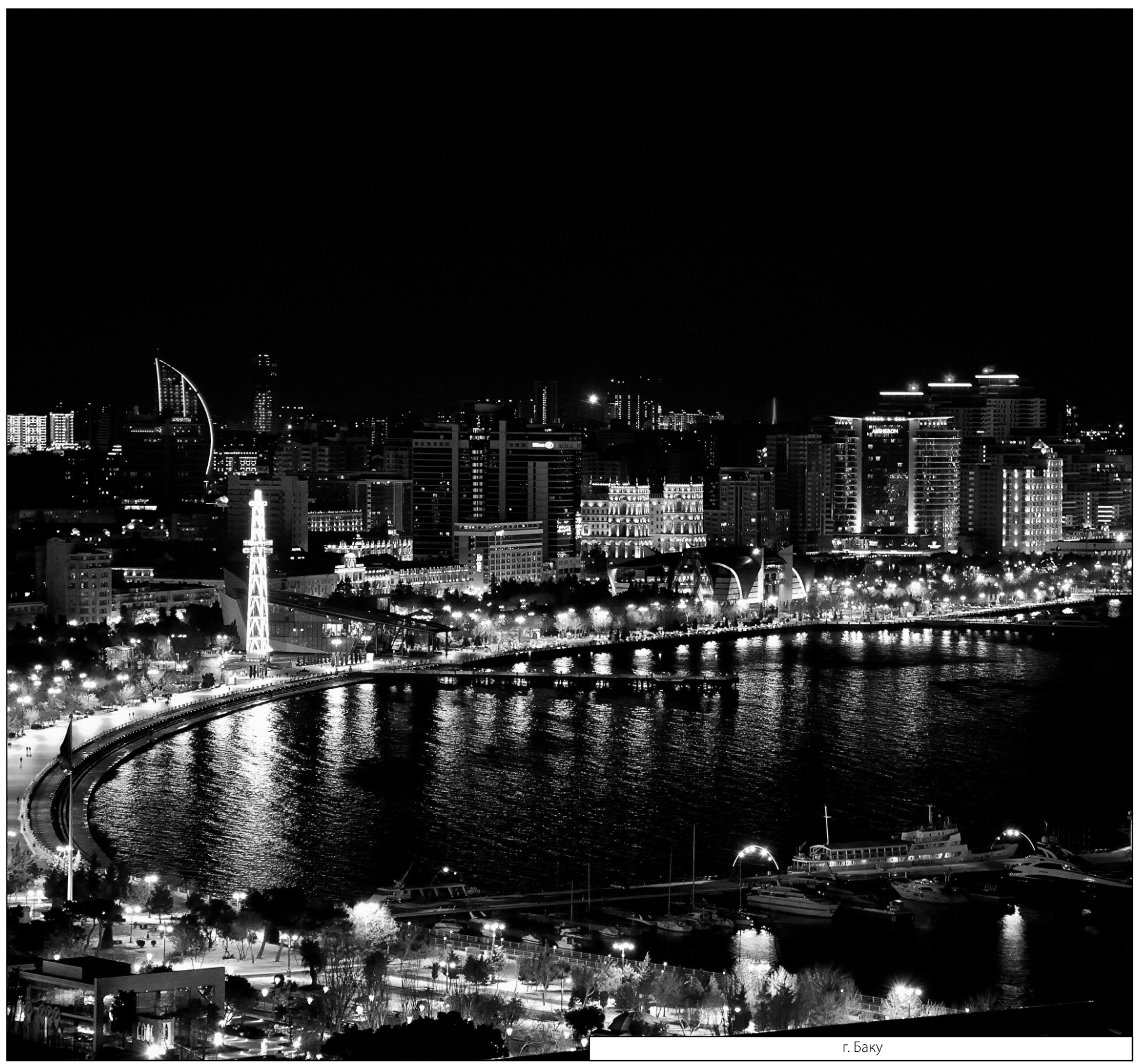

